\title{
O Laboratório de Artrópodes do Instituto Butantan e os aracnídeos peçonhentos
}

\author{
The Butantan Institute's Arthropod \\ Laboratory and Poisonous \\ Arachnids
}

\author{
Sylvia Lucas \\ Laboratório de Artrópodes Instituto Butantan \\ Av. Vital Brasil, 1500 \\ 05503-000 São Paulo — SP Brasil \\ sylvialucas@butantan.gov.br
}

\begin{abstract}
LUCAS, S.: 'O Laboratório de Artrópodes do Instituto Butantan e os aracnídeos peçonhentos.' História, Ciências, Saúde - Manguinhos, vol. 10(3): 1025-35, set.-dez. 2003.

O presente relato é um histórico sobre a origem do Laboratório de Artrópodes do Instituto Butantan, desde a época de sua fundação até a aposentadoria de Wolfgang Bücherl, um dos maiores aracnológos do Brasil, em meados de 1967. Baseia-se nos relatórios anuais de Vital Brazil, diretor do instituto durante o período de 1900 a 1919 e de 1924 a 1927 nos trabalhos publicados nas Memórias do Instituto Butantan e também no meu convívio, a partir de 1961, como assistente de Bücherl, com pesquisadores, pessoal técnico e colaboradores do instituto.

PALAVRAS-CHAVE: Histórico.Instituto Butantan. Laboratório de Artrópodes.
\end{abstract}

LUCAS, S.: 'The Butantan Institute's Arthropod Laboratory and Poisonous Arachnids'. História, Ciências, Saúde-Manguinhos, vol. 10(3): 1025-35, Sept.-Dec. 2003.

The text follows the history of the Butantan Institute's Arthropod Laboratory from its foundation to the mid-1967 retirement of Wolfgang Bücherl, one of Brazil's greatest arachnologists. Information is drawn from several sources: annual reports by Vital Brazil, director of the Institute, from the periods 1900-1919 and 1924-1927; works published as part of Memórias do Instituto Butantan; and my personal experience with the Institute's researchers, technical staff, and contributors, as Bücherl's assistant starting in 1961.

KEYWORDS: historical background, Butantan Institute, Arthropod Laboratory.

\footnotetext{
$\mathrm{O}$
} Instituto Butantan foi fundado em 1900, tendo como principal objetivo a elaboração de um soro e de uma vacina contra a peste que afetava a região do porto de Santos em São Paulo.

O doutor Vital Brazil, médico e primeiro diretor do instituto, logo se empenhou em produzir também um soro hiperimune para o tratamento 
${ }^{1}$ A gravidade dos acidentes ofídicos sempre foi bem maior e de maior impacto do que os causados por aranhas e escorpiões. Em relação a estes últimos, quase não há estatísticas sobre a extensão das ocorrências. Em geral identificam-se apenas acidentes por escorpião ou aranha. A maior dificuldade em produzir as estatísticas sempre foi identificar os animais, que algumas vezes acompanham o acidentado, em geral amassados, incompletos ou podres. dos acidentes causados por serpentes. Tais acidentes em geral eram muito graves, levando à mutilação ou mesmo à morte das vítimas, desconhecendo-se na época qualquer medicamento eficaz. ${ }^{1}$

Já a partir de 1905, Vital Brazil, preocupado com a gravidade de picadas ocasionadas por alguns escorpiões, fez os primeiros testes para produzir um soro para o tratamento desses acidentes. Como não havia um especialista no instituto para identificar os escorpiões, solicitou a ajuda de um zoólogo, R. von Ihering, que os identificou como pertencentes ao gênero Tityus. A falta de escorpiões para obtenção de veneno em quantidade suficiente para imunização dos animais fez Vital Brazil interromper temporariamente seu projeto.

Somente em 1915, Heitor Maurano, médico e aluno de Vital Brazil, daria continuidade aos trabalhos. Utilizou o soro antiescorpiônico produzido a partir do veneno de Buthus quinquestriatus, um escorpião do Egito (Todd, 1909) para tratamento de acidentes em animais de laboratório. Observou, entretanto, que o medicamento não apresentava eficácia alguma nos acidentes causados pelo Tityus. Pôde assim demonstrar que, tal como ocorria com o soro usado no tratamento de acidentes provocados por serpentes, o soro antiescorpiônico deveria ser específico.

Em fase experimental, obteve um soro inoculando o veneno de Tityus em cobaias. Na época, a identificação das espécies era difícil e julgava-se que os exemplares coletados em Minas Gerais constituíam apenas uma variedade mais clara da espécie T. bahiensis, comum em São Paulo. Porém já se sabia que o veneno deste escorpião - de cor amarelada e posteriormente descrito por Lutz e Mello, em 1922, como T. serrulatus - causava acidentes mais graves. Maurano (1915) observou, nesses casos, que as cobaias produziam anticorpos muito lentamente .

Vital Brazil contratou então um profissional para coleta de escorpiões em Minas Gerais. Baseado em sua experiência na elaboração de soros antipeçonhentos, e com os resultados obtidos por Maurano, produziu pela primeira vez em ampla escala um soro antiescorpiônico, usando cavalos como produtores de anticorpos (Brazil, 1918).

Em fins de 1924, quando Vital Brazil reassumiu a diretoria do Instituto Butantan, convidou o professor Jean Vellard para ajudá-lo na identificação de aracnídeos peçonhentos. Vellard, um médico francês especialista em identificação de aranhas, já havia trabalhado com Vital Brazil em Niterói, no Instituto Vital Brazil. Ele foi contratado com a finalidade de estudar os aracnídeos em geral, particularmente os do estado de São Paulo, tanto do ponto de vista da sistemática como do estudo de sua biologia e seus venenos, como consta em relatório anual de 1925. Também foi incumbido de completar e reorganizar o museu de animais peçonhentos.

Vellard trouxera de Niterói diversas aranhas para enriquecer a coleção do instituto e realizou inúmeras excursões para coleta de exemplares, muitas vezes usando o cavalo como meio de locomoção outras usando um automóvel. No acervo encontrou apenas duas aranhas 
caranguejeiras e dois vidros contendo vários exemplares em mau estado de conservação, sem local de captura ou identificação. Em pouco tempo o número de aranhas identificadas já era de 250 , muitas delas novas para a ciência, havendo ainda numerosas sem identificação, por dificuldades diversas.

Quanto à coleção de escorpiões, Vellard cita que encontrou um pequeno número de espécies obtidas do Museu de História Natural de Paris, todas identificadas e guardadas em um armário do museu. Menciona também um vidro que continha exemplares com etiquetas do Museu de Stuttgart, da Alemanha, porém com os nomes apagados. Ainda havia algumas espécies brasileiras, como Tityus babiensis e $T$. stigmurus, e uma espécie de Centrurus. Essa coleção das quais ainda existem diversos exemplares no laboratório, foi o início da coleção de escorpiões do Instituto Butantan, que hoje conta em seu acervo mais de três mil exemplares.

Vellard publicou, em colaboração com Vital Brazil, os primeiros estudos sobre o soro contra o veneno de Lycosa raptoria Walckenaer,1837 (Brazil et al., 1925), estudou a toxicidade do veneno de diversas outras espécies de aranhas, preparou o soro anti ctenus e descreveu também inúmeras espécies novas.

Depois da saída de Vellard — que trabalhou no instituto até outubro de 1927 —, somente a partir de 1931, com o ingresso do doutor Alcides Prado, parasitólogo de formação, o laboratório voltou a apresentar trabalhos de pesquisa. Prado publicou alguns artigos sobre a taxonomia de escorpiões e serpentes e trabalhou no Instituto Butantan de 27 de novembro de 1930 a 28 de abril de 1949. Provavelmente foi iniciativa sua a organização da coleção Araneae, que, conforme o primeiro livro tombo, era única, contendo tanto representantes das Mygalomorphae, como das Araneomorphae.

Em fevereiro de 1939, foi contratado Wolfgang Bücherl, biólogo formado na Alemanha. Seus primeiros trabalhos como assistente de Prado foram sobre a sistemática, a biologia e o veneno dos quilópodes (lacraias). Somente após 1950, Bücherl, já dispondo de espaço maior e como chefe do Laboratório de Zoologia Médica, começou a se interessar por escorpiões e aranhas.

Reorganizou a coleção de aranhas, dividindo-a em duas seções distintas: a de Araneomorphae e a de Mygalomorphae. Ampliou as coleções, sobretudo organizando a recepção dos animais enviados ao instituto pelos fornecedores, que utilizavam o transporte por via férrea, gratuito, idealizado por Vital Brazil.

Bücherl observou que, da grande maioria das aranhas enviadas, somente eram aproveitadas as de interesse médico, para fins de obtenção de veneno e produção de soros antipeçonhentos, a saber, aquelas pertencentes aos gêneros Ctenus e $L y c o s a$, denominações utilizadas na época. As demais eram identificadas superficialmente e em geral inutilizadas. Bücherl começou a incluir esses exemplares nas coleções 
do laboratório. Por meio de correspondência ativa entre ele e os fornecedores, incentivou-os a enviar novos animais, ampliando dessa maneira o acervo científico. Por meio de intercâmbio internacional, enriqueceu as coleções com aracnídeos exóticos.

Devem ser igualmente lembrados os nomes do doutor Alphonse R. Hoge e seus auxiliares, Francisco Cavalheiro e Pedro Villela, do Laboratório de Herpetologia do instituto. Na década de 1950, efetuando excursões científicas às regiões não servidas pelo transporte ferroviário, como boa parte do Centro-Oeste e Norte do país, coletaram os primeiros aracnídeos destas regiões, incluídos também nas coleções.

A responsabilidade maior de Bücherl, contudo, estava voltada para os aracnídeos peçonhentos, uma vez que havia a necessidade de se obter um veneno de boa qualidade para a produção de soros antiaracnídicos. Até então, eram usados os telsos dos escorpiões, situados ao final da cauda, que contêm as duas glândulas de veneno, e de seu macerado obtinha-se o antígeno injetado nos cavalos. Bücherl foi pioneiro na manutenção de escorpiões vivos em laboratório (Bücherl, 1953).

O técnico que trabalhava com ele, José Navas, foi o primeiro a manusear aranhas e escorpiões vivos, procurando imobilizá-los para obter o veneno. Cortando a ponta do ferrão pelo qual o animal injeta o veneno, impossibilitando-o assim de picar, Bücherl estudou o comportamento do escorpião e desenvolveu um modo seguro de prendê-lo, com uma pinça de ponta curva e depois diretamente com a mão, sem que este fosse capaz de inocular o veneno no extrator. Deste modo, utilizando um equipamento artesanal que emitia um estímulo elétrico, pôde-se obter o veneno diretamente do telso, ao mesmo tempo que se mantinham vivos os animais.

Os escorpiões continuavam a ser fornecidos ao instituto por profissionais especializados na coleta. Destacamos aqui o nome de Abrahão Nasser, de Ouro Preto, Minas Gerais, e de Felisberto Miguel Arcanjo, de Mato Dentro, também Minas Gerais, que por muitos anos enviaram ao laboratório elevado número (mais de vinte mil por ano) de escorpiões Tityus bahiensise T. serrulatus, respectivamente.

Se o problema dos acidentes com escorpiões foi resolvido com a produção do soro, os acidentes com aranhas ainda causavam muitas dúvidas quanto à identificação das espécies causadoras.

O primeiro diagnóstico clínico de acidente por aranha do gênero Loxosceles feito no Brasil ocorreu em 1954, no Hospital Vital Brazil do Instituto Butantan (Cardoso et al., 1990). O doutor Gastão Rosenfeld (Rosenfeld et al., 1962), médico chefe deste hospital e do Laboratório de Fisiopatologia do Instituto Butantan, responsável pelo tratamento dos acidentes causados por animais peçonhentos, discutiu com Bücherl a necessidade de dar atenção maior a essas aranhas, uma vez que já havia, no exterior, relatos de acidentes graves causados por elas. Até então os acidentes com seqüelas de grandes necroses, no Brasil, eram atribuídos às aranhas do gênero Lycosa (Brazil et al., 1925). 


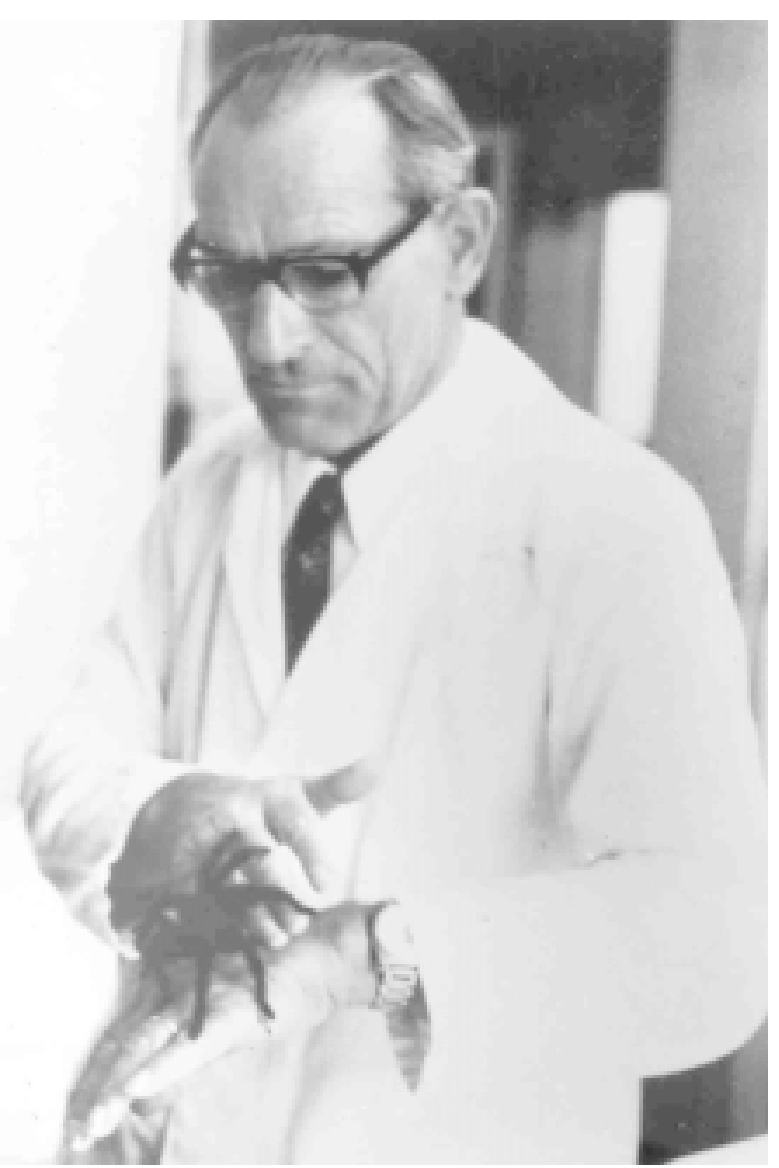

Dr. Wolfgang Bücherl mostra uma aranha caranguejeira. Foto cedida pela filha do doutor Bücherl, llona (c. 1960); também consta dos arquivos do IB da (Divisão de Extensão Cultural); provavelmente tirada por um visitante atendido com freqüência pelo doutor Bucherl.
O LABORATÓRIO DE ARTRÓPODES DO INSTITUTO BUTANTAN

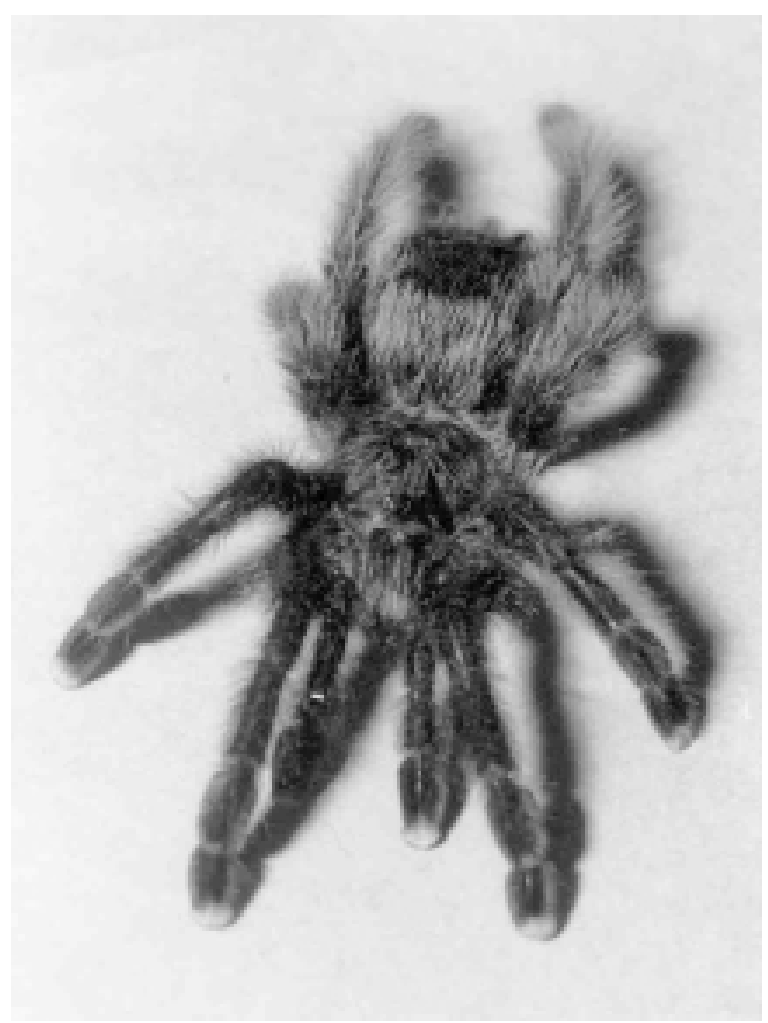

Aranha armadeira (Phoneutria nigriventer). Foto Bücherl

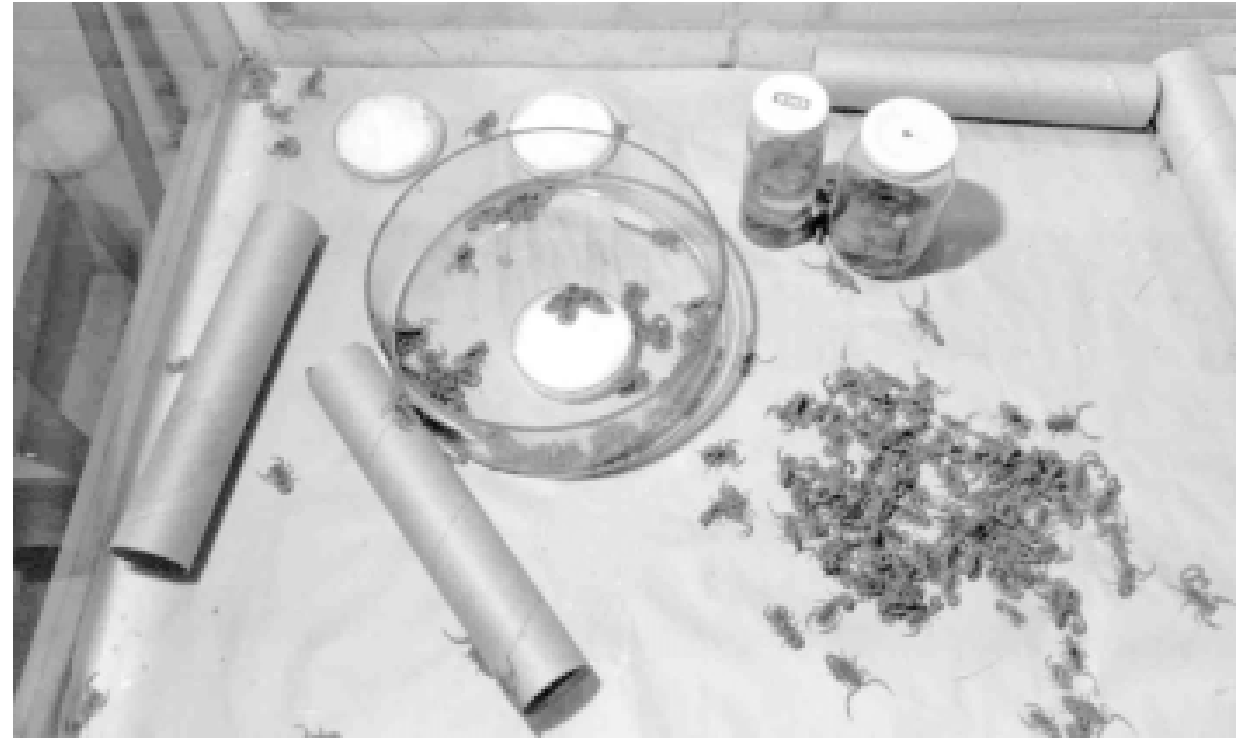

vol. 10(3):1025-35, set-dez. 2003
Avicularia sp., aranha caranguejeira encontrada no resgate da Usina Hidrelétrica de Tucuruí, no Pará. Sem data.

Foto sem, autor. 
Extração do veneno da aranha armadeira, imobilizada por meio de pinça, para se aplicar o estímulo elétrico. Sem data. Foto de Beatriz

Albuquerque, pertencente ao

Arquivo IB,

(Divisão de

Extensão Cultural), sem data.
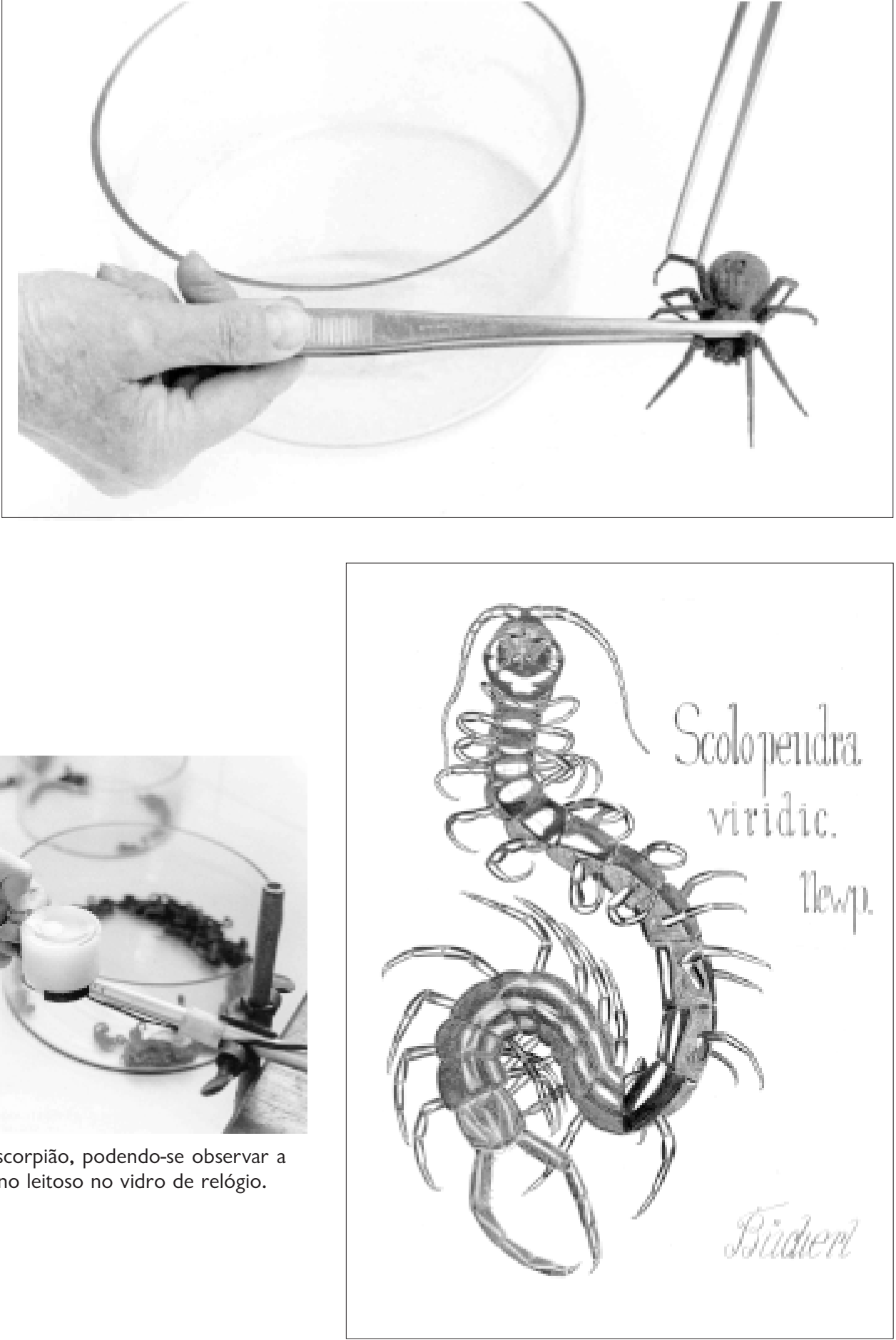

Lacraia. Desenho original em aquarela feito pelo doutor por Dr. W. Bücherl e que por muitos anos ficou exposto no laboratório. Foto de 1939. 


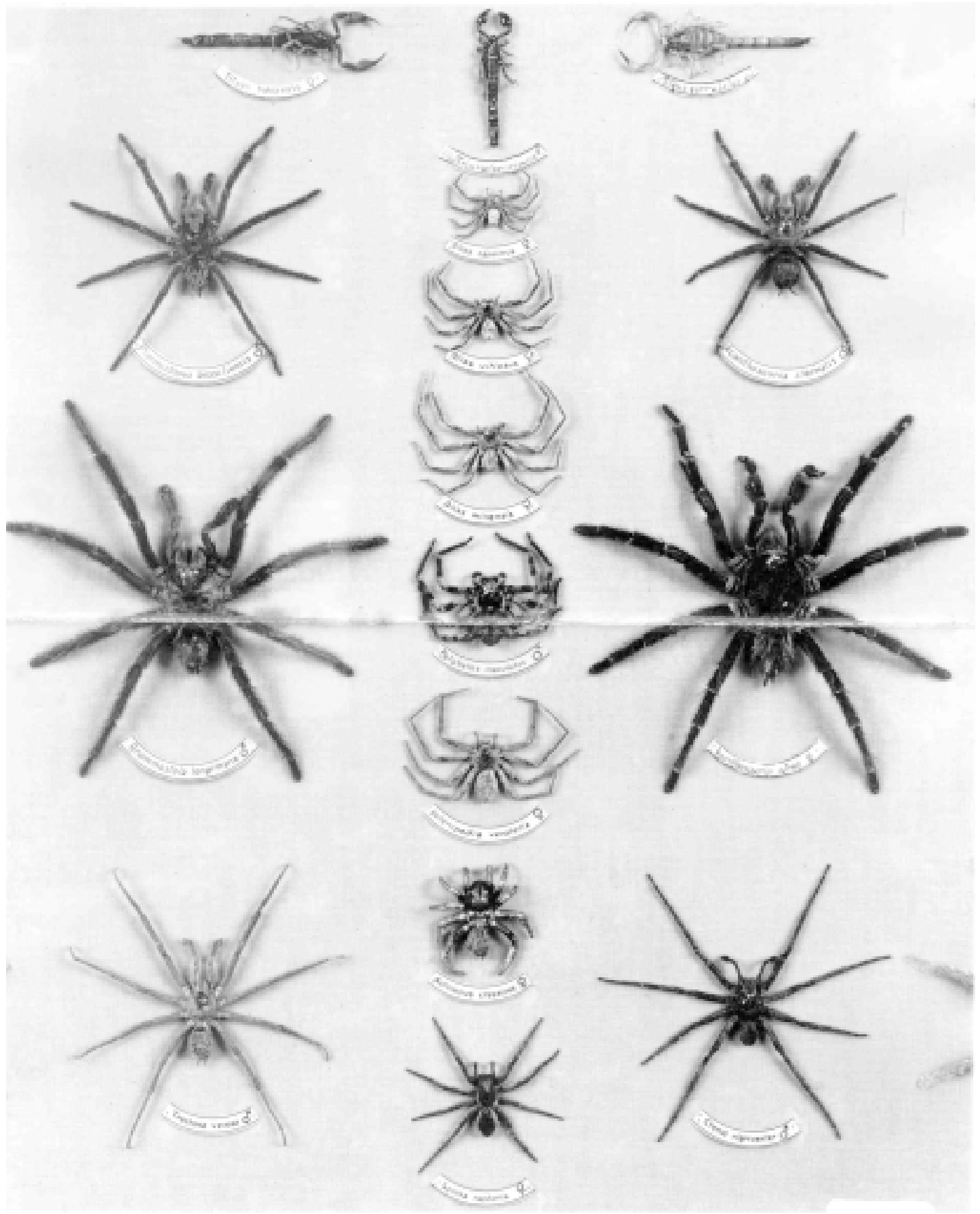

Exposição no Museu Biológico da coleção de aranhas. Foto do oficial do IB feita no antigo Museu Biológico por Seixas, em 1939. 


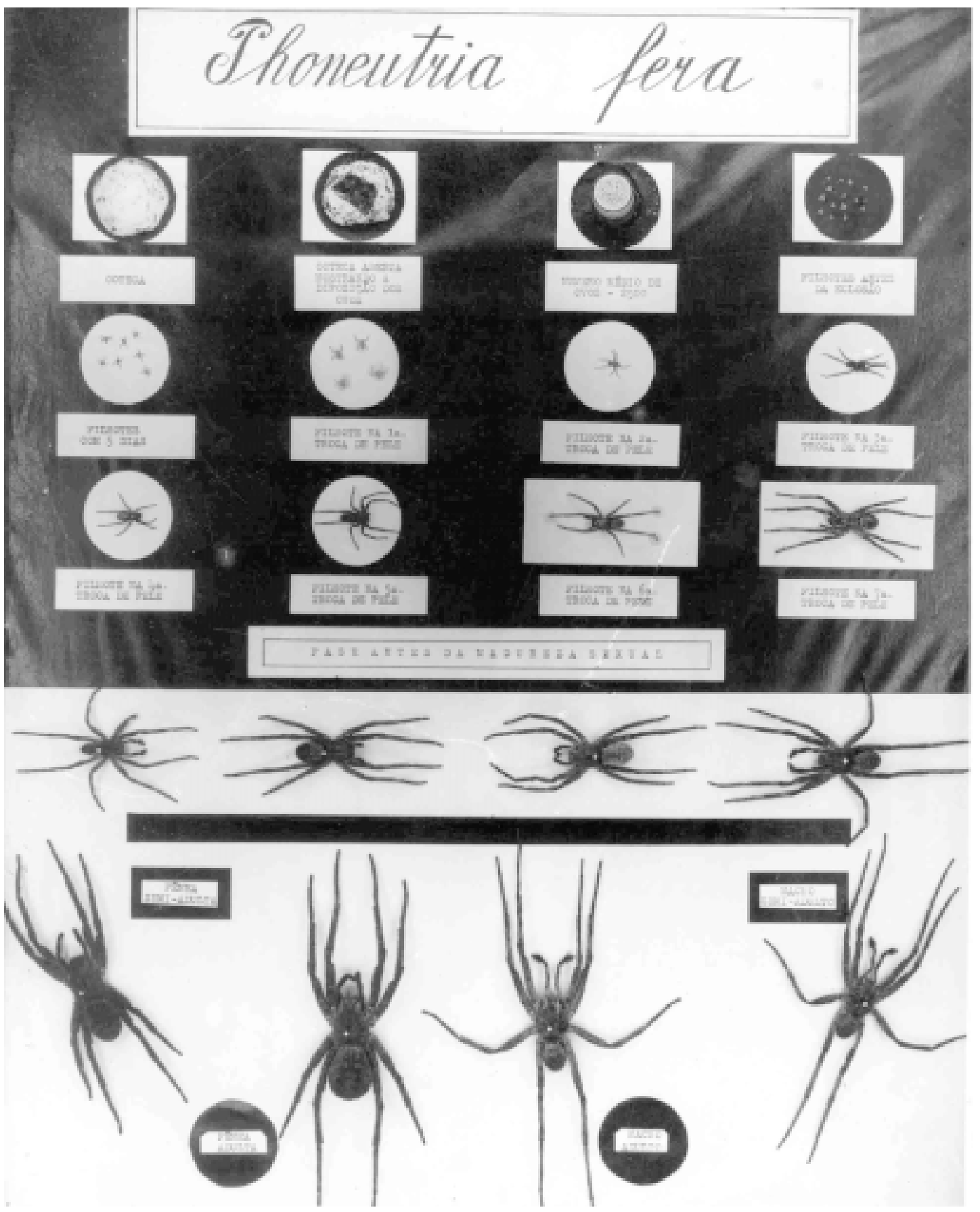

Exposição no Museu Biológico do ciclo da aranha armadeira. Foto do oficial do IB Seixas, 1939. 
Durante os anos 1960, o bairro do Morumbi, em São Paulo, estava sendo alvo de grande desenvolvimento imobiliário, com a construção de inúmeras residências. Um engenheiro, Rodolfo Schwarck, observando as pequenas aranhas do gênero Loxosceles no laboratório, constatou que elas eram abundantes no bairro, principalmente entre os montes de telhas e tijolos estocados ao relento por muito tempo. A equipe do laboratório, sob a orientação de Bücherl, começou a realizar excursões de coleta. O trabalho de um dia rendia a captura de mais de mil exemplares. Com a diminuição do número dessas aranhas no bairro do Morumbi, foram localizados outros focos, por exemplo, nas olarias da Parada de Taipas.

Posteriormente Bücherl, à maneira dos coletores de escorpião, procurou um profissional que fornecesse aranhas ao instituto. Assim, a família de Samuel Helfenstein coletou no próprio instituto e na fazenda pertencente à instituição, situada no município de Araçariguama, em São Paulo, centenas de exemplares. Mais tarde a tarefa foi continuada pela familia de Walter e Esmarel Serode, moradores daquele município. A espécie coletada com maior freqüência era a L. gaucho Gertsch, 1962, identificada por Bücherl como L. rufescens (Dufour, 1820), e, em menor quantidade, L. laeta (Nicolet, 1849), na época identificada como L. rufipes (Lucas, 1834) (Bücherl, 1960-62).

A dificuldade de obtenção do veneno em quantidade suficiente era grande, por causa do tamanho reduzido dos exemplares. No Instituto Butantan os primeiros estudos, realizados pelo doutor R. Furlanetto (Furlanetto, 1961) visando à produção de um soro no Brasil, foram feitos a partir de um macerado do cefalotórax das aranhas, região anterior do corpo que contém as duas glândulas de veneno. Somente alguns anos mais tarde, com o aperfeiçoamento do equipamento utilizado para a coleta do veneno dos escorpiões, a metodologia começou a ser empregada também para a obtenção do veneno dessas aranhas, e o soro antiloxoscélico começou a ser produzido em escala industrial. Hoje em dia é um produto regularmente usado no tratamento dos acidentes.

A partir de 1964, a existência de alguns 'focos' de aranhas conhecidas como viúvas-negras (pertencentes ao gênero Latrodectus) em diversas praias do Rio de Janeiro despertou o interesse do instituto (Bücherl, 1965). Bücherl e sua equipe capturaram centenas de exemplares, e o veneno foi usado para a produção de um soro experimental. A freqüência muito baixa de acidentes ocasionou a interrupção da produção.

Bücherl aposentou-se em fins de 1967, deixando organizado o Laboratório de Artrópodes como unidade subordinada à diretoria do Instituto Butantan. Assumi esse laboratório como sua substituta e, posteriormente, como diretora efetiva, cargo que exerci por mais de trinta anos.

Atualmente trabalham no laboratório seis pesquisadores científicos, três assistentes de pesquisa, diversos estagiários e uma equipe técnica, constituindo o maior núcleo de aracnólogos da América do Sul. Diversos 
projetos de pesquisa estão em desenvolvimento, principalmente com o apoio financeiro da Fundação de Amparo à Pesquisa do Estado de São Paulo (Fapesp). Cito aqui os mais importantes: Estudo da biodiversidade de aracnídeos e quilópodes do estado de São Paulo, integrando o projeto Biota/Fapesp, desenvolvido pelos pesquisadores do laboratório e de diversas universidades; Estudo bioquímico dos venenos dos escorpiões do gênero Tityus, desenvolvido por mim, em colaboração com o doutor Lourival Possani, do Instituto de Biotecnologia da Universidade do México; Estudo da hemolinfa de aranhas caranguejeiras, desenvolvido em colaboração com os pesquisadores do Instituto de Ciências Biomédicas da Universidade de São Paulo.

As diversas coleções sistemáticas do instituto estão sendo reorganizadas, passando por processo de informatização e vêm-se continuamente ampliando. No biotério aumentado, que fica em prédio independente, inaugurado em 1995, são mantidas as diversas espécies de aranhas e escorpiões dos quais são extraídos os venenos necessários à pesquisa e produção de soros. A equipe técnica orienta a população sobre os aracnídeos peçonhentos e são ministradas aulas, cursos e palestras sobre o tema.

Ao que parece, só nos últimos anos começou a se dar importância maior ao estudo do veneno de escorpiões e aranhas e de invertebrados em geral. Acredito que a dificuldade de obter veneno em quantidade suficiente foi sempre um grande problema, hoje superado pelos equipamentos de maior precisão. As balanças usadas por Bücherl permitiam apenas uma estimativa das quantidades de peçonha. Com as balanças atuais, pode-se trabalhar com microgramas.

Sobretudo a partir da coleta de veneno puro, colhido diretamente das glândulas das aranhas ou dos escorpiões, puderam ser desenvolvidos muitos estudos — tanto brasileiros quanto realizados em colaboração com pesquisadores de outros países — sobre a composição de venenos, isolamento de suas frações tóxicas, pesquisas de fisiologia e farmacologia. Os estudos dos componentes tóxicos dos venenos e suas estruturas têm demonstrado utilidade, como, por exemplo, o soro antiescorpiônico que desenvolvemos, cuja ação protege contra as três principais espécies causadoras de acidentes no Sudeste e Nordeste brasileiros. Outros pesquisadores dedicam-se a projetos sobre venenos de escorpiões e aranhas, isolando peptídeos que agem sobre certas bactérias patogênicas para o ser humano. Assim tem sido dada continuidade aos trabalhos iniciados por cientistas como Vital Brasil e Bücherl. 


\section{REFERÊNCIAS BIBLIOGRÁFICAS}

Brazil, V. et al.

1925

Brazil, V.

Bücherl, W.

Bücherl, W.

1960-62

Bücherl, W.

1953

Cardoso, J. L. C. et al. 1990

Furlanetto, R. S. 1961

Maurano, H. R. 1915

Rosenfeld, G. V. et alii 1962

Todd, C.

Vital Brazil, L. 1996
'Contribuição ao estudo do veneno das aranhas'.

Mem. Inst. Butantan, no 2, pp. 3 -71.

'Soro antiescorpionico'.

Mem. Inst. Butantan, no 1, pp. 47- 50.

Latrodectus e latrodectismo na América do Sul. I Descrição do macho de da população de Latrodectus, Walckenaer, 1805 das praias do Rio de Janeiro e da Guanabara'. Mem. Inst. Butantan, no 32, pp. 95-100.

"Aranhas do gênero Loxosceles e Loxoscelismo na América do Sul.

I Introdução, Comentários Bibliográficos, Caracterização da Subfamília Loxoscelinae, do gênero Loxosceles e enumeração das espécies da América do Sul'. Mem. Inst. Butantan, no 30, pp. 167-86.

'Escorpiões e escorpionismo no Brasil. I. Manutenção de escorpiões em viveiros e extração de seu veneno'. Mem. Inst. Butantan, vol. 25, no 1, pp. 53-82.

'Primeiro diagnóstico clínico de loxoscelismo na casuística do hospital Vital Brazil'. Mem. Inst. Butantan, no 52 (supl.), p. 81.

Estudos sobre a preparação do soro antiloxoscélico. Tese de doutoramento, São Paulo, Faculdade de Farmácia e Odontologia da Universidade de São Paulo.

Do escorpionismo. Tese de doutoramento, Rio de Janeiro.

Faculdade de Medicina do Rio de Janeiro, pp. 1- 267.

'O problema dos acidentes licósico e loxoscélico'.

Ciência e Cultura, vol. 14, no 4, p. 253.

'An anti serum for scorpion venom'. Journal of Hygiene, vol. IX, n⿳ำ 1 .

'Vital Brazil mineiro da Campanha, uma genealogia brasileira'. Rio de Janeiro, Leal Vital Brazil. 